\title{
Performance Modeling of MAC and Multipath Routing Interactions in Multi-hop Wireless Networks
}

\author{
Xin Wang, J.J. Garcia-Luna-Aceves, Hamid R. Sadjadpour \\ University of California, Santa Cruz
}

USA

\section{Introduction}

For multi-hop wireless networks, the performance experienced by each node is a complex function of the following factors: 1 ). the signals used at the physical layer; 2 ). the radio topology of the network; 3). the transmission scheduling established at the MAC layer, 4). the route selection results of the network layer.

The input of any above component is partially decided by the output of the other components, e.g. 1). transmission scheduling: radio topology decides whether links interfere with others, and route selection decides which links will be used for transmissions; 2 ). route selection: the radio topology of the network influences the route selection results directly; since routing control packets are transmitted as the data packets at the MAC layer, the transmission scheduling decides how the routing information is propagated throughout the network, etc.

Hence, analyzing the performance of protocol stacks in a wireless network must consider the interactions between the different layers. In fact, a cross-layer perspective to both performance analysis and protocol design brought to attention with recent advances in wireless networks. It is critical for us to treat the entire protocol stack as a single algorithmic construct in order to improve the performance, and in general, it is not meaningful to speak about a MAC or a routing protocol in isolation.

This chapter introduces a modeling framework for the characterization of the performance attained with a MAC protocol working together with different packet forwarding disciplines on top of a realistic physical layer. We also analyzed how different packet forwarding disciplines interact with different channel access schemes to influence the system performance.

\section{Related work}

A significant amount of work (e.g.,(Gitman, 1975; Tobagi, 1980a;b; Boorstyn et al., 1987; Tobagi \& Brazio, 1983; Shepard, 1996; Chhaya \& Gupta, 1997; Wang \& Garcia-Luna-Aceves, 2002; Wu \& Varshney, 1999)) has been reported on the analytical modeling of contention-based MAC protocols. However, there are very few prior works discussing the interaction between MAC and packet forwarding in wireless networks, and most of them are based on the discussion of simulation results focusing on contention-based MAC protocols and single-path routing. Das et al. (Das et al., 2000)(Das et al., 2001) use a 
simulation model to show that the interplay between routing and MAC protocols affects the performance significantly in the context of AODV and DSR. Royer et al. (Royer et al., 2000) explore the behavior of different unicast routing protocols when run over varying contention-based MAC protocols. They find that table-driven routing protocols behave in much the same way when used with different MAC protocols, while an on-demand routing protocol is more sensitive to the functionality of the MAC protocol, because it requires feedback mechanisms at the MAC layer. Barrett et al. (Barrett et al., 2003) conducted a comprehensive simulation study to characterize the interaction between MAC and routing protocols, node speed, and data rates in mobile ad-hoc networks. They concluded that no combination of MAC and routing protocol was better than other combinations over all mobility models and response variables. Bai et al. (Bai et al., 2003) proposed a framework consisting of various protocol-independent metrics to capture interesting mobility characteristics, including spatial(temporal) dependence and geographic restrictions. They observed that the mobility pattern influences the connectivity graph that in turn influences the protocol performance. In addition, they did a preliminary investigation of the common building blocks of MANET routing protocols, the effect of mobility on these building blocks and how they influence the protocol as a whole. Vadde et al. (Vadde \& Syrotiuk, 2004) studied the impact of QoS architectures, routing protocols, and MAC protocols on service delivery in MANETs, using interaction graphs to visualize the two-way interactions between factors. Vadde et al. (Vadde et al., 2006) used statistical design of experiments to study the impact of factors and their interaction on the service delivery in a MANET. They considered the factors of QoS architecture, routing protocols, medium access control protocols, offered loads, and node mobility. Through statistical analysis of the simulation results, they found that the MAC protocol and its interaction with the routing protocol are the most significant factors influencing average delays, and that throughput is not much impacted by the type of routing protocol used. The bulk of the analytical modeling of wireless ad hoc networks has concentrated on the analysis of MAC protocols in fully-connected segments of networks (e.g., satellite networks, cellular networks, or single-hop wireless LANs (WLANs)), because they are simpler to analyze than multihop networks. The majority of this work has followed the formalism and assumptions introduced by Abramson (Abramson, 1970; 1977) for the analysis of the ALOHA protocol, and by Tobagi and Kleinrock (Kleinrock \& Tobagi, 1975; Tobagi \& Kleinrock, 1975) for the analysis of the carrier sense multiple access (CSMA) protocol. The model typically adopted assumes that all nodes have infinite buffers and transmissions are scheduled according to independent Poisson point processes. This implies that packets which were either inhibited from being transmitted or were unsuccessfully transmitted are rescheduled after a "sufficiently long" randomized time out to preserve the Poisson property (i.e., no correlation between new packet arrivals and their rescheduling). Packet lengths are exponentially distributed and are independently generated at each transmission attempt (including retransmissions). In many cases, acknowledgments are assumed to happen instantaneously or, in cases where propagation delay is taken into account, acknowledgment traffic is simply ignored, and periods of collisions are restricted to the propagation time, after which all other nodes are able to perceive any activity in the channel (through the single-hop and perfect-channel assumptions). Regarding the quality of the radio links, they are generally considered error free, and the event of unsuccessful transmission is restricted to packet collisions at the receiver. Examples where such assumptions have been made include (Roberts, 1975) (Kleinrock \& Lam, 1975) (Colvin, 1983) (Lo \& Mouftah, 
1984) (Karn, 1990) (Barghavan et al., 1994), (Fullmer \& Garcia-Luna-Aceves, 1995), and (Fullmer \& Garcia-Luna-Aceves, 1997).

Other works consider physical-layer aspects more explicitly within the context of single-hop scenarios. Raychauduri (Raychauduri, 1981) analyzed slotted ALOHA with code division; Gronemeyer and Davis (Davis \& Gronemeyer, 1980) considered spread-spectrum slotted ALOHA with capture due to time of arrival. Musser and Daigle (Musser \& Daigle, 1982) derived the throughput of pure ALOHA with code division. Pursley (Pursley, 1983) studied the throughput of frequency-hopped spread-spectrum communications for packet radio networks. In other cases, the error-free link assumption was relaxed and multipath fading channels where considered while preserving other original assumptions (e.g., Poisson scheduling). This is the case in the works by Arnbak and Blitterswijk, who studied the capacity of slotted ALOHA in Rayleigh-fading channels (Arnbak \& Blitterswijk, 1987). More recently, with the advent of the IEEE 802.11 standard for WLANs, its operation. Unfortunately, the vast majority of this effort has considered only single-hop networks under ideal channel conditions (Carvalho \& Garcia-Luna-Aceves, 2003), (Bianchi, 2000), (Cali et al., 2000), (Foh \& Zukerman, 2002), (Kim \& Hou, 2003). A gap still remains on the modeling of multi-hop wireless networks under specific combinations of MAC protocols and packet-forwarding disciplines in a way that the impact of their interactions is taken into account in the performance evaluation of each node.

\section{Protocol interactions}

In this section we address the interactions between protocol stacks and the classification of different feedback information. The most important modeling factor in the interaction between the MAC layer and the physical layer is the probability that a frame transmission is successful, because it is the basis for the scheduling of either transmissions or retransmissions of frames by the MAC protocol. The output of any routing protocol is a subset of nodes in the network, which forms a specific routing path, and this subset varies at different stages of routing protocol. For example, when there is no existing route, the subset includes every nodes that are involved in the route discovery (e.g. initiating route requests, sending route replies or forwarding routing control packets, etc.). After the route is established, the subset consists of the nodes that form a specific routing path or are responsible for the route maintenance. In this paper, we focus on the interaction of routing and MAC protocols that takes place after routes have been established. Accordingly, we are mainly interested on the interaction between the MAC protocol and the number of next-hops per destination, which are used according to specific forwarding rules. Our model captures this interplay by means of the probability that a transmission schedule is collision-free. We classify the feedback information that flows across layers into two classes: (a) Feedback information that does not depend on the activity of other nodes (e.g., whether a node has data packets to send); and (b) feedback information dependent on the activities of all other nodes (e.g., the successful transmission probability of each frame, or the probability that a transmission schedule is collision-free). The MAC and physical (PHY) layers are coupled with each other tightly at small time scales encompassing just a few packet transmissions. On the other hand, route selections are made based on the end-to-end information between the traffic source and destination; hence, this activity interacts with the MAC layer at large time scales, i.e., hundreds of packet transmissions. Based on the above considerations, we investigate the interaction between protocol layers from small time scales (MAC and PHY) to large time scales (MAC and routing). 


\section{Model formulation}

We assume that each node $k$ transmits frames according to a transmission rate (transmission probability) $\tau_{k}$, and retransmissions are independent of previous attempts. All nodes along the selected routing path always have packets to send (i.e., the transmission queue of each node is always nonempty). If there are more than one nodes transmit to the same receiver simultaneously, the whole frame transmission is a failure.

\subsection{Successful frame reception probability}

Let $P_{k}^{r}$ denote the received signal power at node $r$ for a signal transmitted by node $k$. Let $V$ denote the finite set of $|V|=n$ nodes spanning the network under consideration, and $V_{r} \subseteq V$ the subset of nodes that are in the reception range of node $r . \quad V_{r}^{\prime} \subseteq V_{r}$ is the subset of nodes that are on the selected routing path. $V_{r}$ incorporates the topology information, while $V_{r}^{\prime}$ includes the feedback information from the network layer. At time $t$, the signal-to-interference-plus-noise density ratio $\operatorname{SINR}_{i}^{r}(t)$ for a signal transmitted by node $i$ and received at node $r$ is (Tse \& Hanly, 1999):

$$
\operatorname{SINR}_{i}^{r}(t)=\frac{P_{i}^{r}(t)}{\sum_{j \in V_{r}^{\prime}} \chi_{j}(t) P_{j}^{r}(t)+\sigma_{r}^{2}},
$$

where $\sigma_{r}^{2}$ is the background or thermal noise power at the front end of the receiver $r . \chi_{j}(t)$ is an on/off indicator,

$$
\chi_{j}(t)= \begin{cases}1, & \text { if } j \text { transmits to } r \text { at time } t, \\ 0, & \text { otherwise. }\end{cases}
$$

$\chi_{j}(t)$ reflects MAC layer transmission scheduling(contention) results. Let $\left|V_{r}^{\prime}\right|=n_{r}$, there are exactly $2^{n_{r}-1}$ combinations of active transmitting nodes (interferers) in $V_{r}^{\prime}$, excluding the transmitter $i$ itself. In what follows, let $\left\{c_{i k}^{r}\right\}_{k=1, \ldots, 2^{n_{r}-1}}$ denote the set of such combinations. Additionally, $c_{i 0}^{r}$ is the combination corresponding to the case when no interferers of $r$ transmit. Let $\gamma\left(c_{i 0}^{r}\right)$ denote the SINR at node $r$ for a bit transmitted by $i$ when none of $r^{\prime}$ s interferers transmits:

$$
\gamma\left(c_{i 0}^{r}\right)=\frac{P_{i}^{r} L_{i}}{\sigma_{r}^{2}}
$$

where $L_{i}$ is the spreading gain (or bandwidth expansion factor) of the spread-spectrum system. If $K$ is the length of the frame in bits, and $P_{b}(\gamma)$ is the bit-error probability for a certain SINR level $\gamma$, then the probability of successful frame reception $\left(f\left(c_{i 0}^{r}\right)\right)$ when only the sender transmits in the neighborhood of an intended receiver is:

$$
f\left(c_{i 0}^{r}\right)=\left\{1-P_{b}\left[\gamma\left(c_{i 0}^{r}\right)\right]\right\}^{K} .
$$

The probability $q$ that a transmitted packet does not collide equals the probability that no neighbor of the receiver transmits and the packet is received correctly (we do not consider the partial overlapping case in this paper). The probability that no neighbor transmits equals

$$
P\{\text { no neighbor transmits }\}=\prod_{j \in V_{r}^{\prime}}\left(1-\tau_{j}\right)
$$

Hence, using conditional probability, $q$ can be expressed as

$$
q=f\left(c_{i 0}^{r}\right) \prod_{j \in V_{r}^{\prime}}\left(1-\tau_{j}\right)
$$


We analyze the performance of the MAC layer following the approach introduced by Carvalho et al. (Carvalho \& Garcia-Luna-Aceves, 2004) and Bianchi's model (Bianchi, 2000). The MAC protocols we seek to model adjust their behavior dynamically according to the feedback information of the PHY and network layers to maximize the number of successful transmissions. Accordingly, we approximate the operation of the MAC protocols by assuming that these protocols in steady-state can be represented by a time-invariant function $h_{i}(\cdot)$ relating the successful transmission probability $q_{i}$ with the steady-state scheduling rate $\tau_{i}$,

$$
\tau_{i}=h_{i}\left(q_{i}\right), i \in V,
$$

where the subscript $i$ in the mapping function $h_{i}(\cdot)$ denotes a node-specific instantiation of the MAC protocol in use. Let $\mathcal{C}_{i}^{r}$ denote the random variable that indicates the occurrence of a specific combination $c_{i k}^{r}$ of interferers. The probability that the set of active interferers is $c_{i k}^{r}$, i.e., $P\left\{\mathcal{C}_{i}^{r}=c_{i k}^{r}\right\}$ is a function of the MAC-dependent transmission probabilities $\tau_{i}$,

$$
P\left\{\mathcal{C}_{i}^{r}=c_{i k}^{r}\right\}=\prod_{m \in c_{i k}^{r}}\left(1-\tau_{m}\right) \prod_{n \in c_{i k}^{r}} \tau_{n}
$$

where $\overline{c_{i k}^{r}}$ denotes the complement set of $c_{i k}^{r}, V_{r}^{\prime}-\left\{c_{i k}^{r}\right\}$. The probability $q_{i}$ that a frame transmitted by $i$ is successfully received can be obtained as follows by considering the set $\left\{c_{i k}^{r}\right\}_{k=1, \ldots, 2^{n_{r}-1}}$ of all possible combinations of active nodes in $V_{r}^{\prime}$ :

$$
\begin{aligned}
q_{i} & =P\{\text { successful frame reception }\} \\
& =\sum_{k} P\left\{\text { successful frame reception, } \mathcal{C}_{i}^{r}=c_{i k}^{r}\right\} \\
& =\sum_{k} P\left\{\text { succ. frame reception } \mid \mathcal{C}_{i}^{r}=c_{i k}^{r}\right\} P\left\{\mathcal{C}_{i}^{r}=c_{i k}^{r}\right\} \\
& =\sum_{k} f\left(c_{i k}^{r}\right) P\left\{\mathcal{C}_{i}^{r}=c_{i k}^{r}\right\},
\end{aligned}
$$

Recall that $c_{i 0}^{r}$ denotes the combinations corresponding to the case when no interferer of receiver $r$ transmit, i.e., $c_{i 0}^{r}=\{\varnothing\}$, meaning that $\overline{c_{i 0}^{r}}=V_{r}^{\prime}$, then we can approximate $q_{i}$ as follows:

$$
q_{i} \approx f\left(c_{i 0}^{r}\right) P\left\{\mathcal{C}_{i}^{r}=c_{i 0}^{r}\right\}
$$

From Eq. (8),

$$
q_{i}=f\left(c_{i 0}^{r}\right) \prod_{j \in V_{r}^{\prime}}\left(1-\tau_{j}\right) .
$$

After the linear approximation using the Taylor series expansion (justified in (Carvalho \& Garcia-Luna-Aceves, 2004)), we have

$$
\tau_{i}=h_{i}\left(q_{i}\right) \approx a q_{i} \text {, where } a=h_{i}^{\prime}(0),
$$

From Eq. (12),

$$
q_{i}=f\left(c_{i 0}^{r}\right) \prod_{j \in V_{r}^{\prime}}\left(1-a q_{j}\right) .
$$

If we assume $a<<1$, and because $0 \leq q_{i} \leq 1$, we can approximate the previous products as follows:

$$
q_{i} \approx f\left(c_{i 0}^{r}\right)\left(1-a \sum_{j \in V_{r}^{\prime}} q_{j}\right)
$$

From Eq. (12) and Eq. (14), we can obtain the functional form $h_{i}\left(q_{i}\right)$ by which the MAC layer relates the steady-state transmission probability $\tau_{i}$ with the successful transmission probability $q_{i}$. 


\subsection{End-to-end throughput}

Given that all nodes along an active path are assumed to be saturated, the average MAC layer one-hop throughput for any node $i$ carrying traffic is

$$
S_{i}=\frac{E\{\text { Data Payload }\}}{\overline{T_{i}}} .
$$

where $\overline{T_{i}}$ is the average service time of node $i$. We note that since $\overline{T_{i}}$ varies across different nodes due to the topology information and traffic distributions, $S_{i}$ is per-node throughput. We denote the end-to-end throughput as

$$
S_{E}=\min _{k=1}^{h_{j}}\left\{S_{1}, S_{2}, \ldots, S_{k}, \ldots, S_{h_{j}}\right\}
$$

where $h_{j}$ is the hop length of path $j, S_{k}$ is the average one-hop throughput of hop $k$, defined in Eq. (15).

\subsection{Interaction with number and type of paths}

Multipath routing protocols adapt different constraints for the establishment of next hops to destinations. The existing multipath routing protocols can be classified according to the type of paths they use:

1. Node-disjoint paths (Ye et al., 2003), which are paths to a destination in which a node appears in at most one path.

2. Link-disjoint paths (Marina \& Das, 2001) (Nasipuri et al., 2001), which are paths to a destination in which the same pair of nodes defining a link can appear in at most one path.

3. Minimum-cost paths (Lee \& Gerla, 2001), which are paths to a destination that have the minimum cost amongst all available paths. These paths need not be link or node disjoint.

Because there is no standard definition of minimum-cost for multipath routing protocols, we focus on the study of node-disjoint routing and link-disjoint routing. We use Dijkstra's shortest path algorithm to form the multipath routing set. We choose hop-count as the routing distance metric. The first selected path is the one with the shortest distance between the source and the destination. A path will be added to the selected routing set if: 1). it has the shortest distance among all the unselected paths; 2). it satisfies the node-disjoint or link-disjoint constraint with previous selected paths. If there are more than one path with the same distance, we will select the path with the smaller IP address. We continue this process until no more paths can be added. In our modeling framework, the routing information is fed into $V_{r}^{\prime}, c_{i k}^{r}$ and $S_{E}^{f}$, separately. We extend the definition of interference matrix (Carvalho \& Garcia-Luna-Aceves, 2004) to take into account the effect of routing factors. As indicated in Eq. 11, in order to calculate $q_{i}$, we need to know the set of interferers for each transmitter-receiver pair. We select a node as a potential interferer if and only if: (a) The received interference signal power at the receiver is above the carrier sensing threshold, as indicated in (Carvalho \& Garcia-Luna-Aceves, 2004); and (b) it is on at least one of the routing paths. 


\subsection{Interaction with packet forwarding disciplines}

Once routing paths are formed, nodes use different forwarding rules to select their successors. Opportunistic routing protocols (Biswas \& Morris, 2005) (Chachulski et al., 2007) have been proposed to exploit the benefits of cooperative diversity and path diversity techniques. To simplify our analysis, we classify the different routing forwarding rules into the following types:

1. Single-copy forwarding: A node selects its neighbor with the smallest distance to the destination as the successor, and the smallest address is chosen if there are multiple successors with the same distance.

2. Multiple-copy forwarding: A node selects all successors for forwarding to a destination.

3. P-persistent opportunistic forwarding: A node selects a given successor to forward a packet towards a destination with a probability $p_{f}$.

As in Section 4.3, the routing forwarding rule impacts the calculation of $\operatorname{SINR}_{i}^{r}(t), c_{i k}^{r}$ and $q_{i}$, which influences the conditional probability of successful frame reception $\left(f\left(c_{i 0}^{r}\right)\right)$ and the mapping function $h_{i}($.$) .$

\section{Modeling contention-based MAC: 802.11 DCF}

In this Section, we extend the prior model proposed by Carvalho et al. and Bianchi's model to study the interactions between 802.11 DCF and different packet forwarding methods. Given the backoff time characterization in $802.11 \mathrm{DCF}$, the average service time is $\bar{T}=\bar{T}_{B}+\bar{T}_{S}$, where $\bar{T}_{B}$ is the average backoff time, $\bar{T}_{S}$ is the average time to successfully transmit a packet at the end of the backoff operation. In order to obtain $\bar{T}_{B}, \bar{T}_{S}$, we first need to calculate the probability that a transmission is successful $\left(p_{s}^{i}\right)$, the probability that the channel is idle $\left(p_{i}^{i}\right)$, and the probability that a collision occurs $\left(p_{c}^{i}\right)$. The transmission probability $\tau_{i}$ of each node $i$ is

$$
\tau_{i}=\frac{2\left[1-2\left(1-q_{i}\right)\right]}{\left[1-2\left(1-q_{i}\right)\right]\left(W_{\min }+1\right)+\left(1-q_{i}\right) W_{\min }\left(1-\left(1-q_{i}\right)^{m}\right)}
$$

where $W_{\text {min }}$ is the minimum contention window size specified for the backoff operation, $m$ is the standard-defined maximum power used to set up the maximum contention window size, i.e., $W_{\max }=2^{m} W_{\min }$. Eq. (17) gives us the functional form $h_{i}\left(q_{i}\right)$ by which the MAC layer relates the steady-state transmission probability $\tau_{i}$ with the successful transmission probability $q_{i}$. Then we could derive a first order approximation for it using Taylor series expansion and express $\tau_{i}$ in terms of $q_{i}$

$$
\tau_{i}\left(q_{i}\right)=\frac{2 W_{\min }}{\left(W_{\min }+1\right)^{2}} q_{i}
$$

when we consider all nodes in the topology, can be rewritten in the matrix notation $\tau=a \mathbf{q}$, where $\tau=\left[\begin{array}{llll}\tau_{1} & \tau_{2} & \ldots & \tau_{n}\end{array}\right]^{T}, a=2 W_{\min } /\left(W_{\min }+1\right)^{2}$, and $\mathbf{q}=\left[\begin{array}{llll}q_{1} & q_{2} & \ldots & q_{n}\end{array}\right]^{T}$. The probability that there exists some node from $V_{r}^{\prime}$ transmitting a frame while node $i$ is in backoff is

$$
p_{t r}^{i}=1-\prod_{j \in V_{r}^{\prime}}\left(1-\tau_{j}\right)
$$

The probability $p_{s u c}^{i}$ that a transmission is successful is the probability that some node in $V_{r}^{\prime}$ transmits successfully, conditioned on the fact that at least one node in $S_{i}$ attempted to 
transmits, i.e.,

$$
\begin{aligned}
p_{\text {suc }}^{i} & =\frac{\sum_{k \in S_{i}} P\{k \text { succeed } \mid k \text { transmits }\} P\{k \text { transmits }\}}{p_{t r}^{i}} \\
& =\frac{\sum_{k \in S_{i}} q_{k} \tau_{k}}{p_{t r}^{i}}
\end{aligned}
$$

Then, according to Bianchi's model, the probability that a transmission is successful is $p_{s}^{i}=p_{t r}^{i} p_{s u c}^{i}$; the probability that the channel is idle is $p_{i}^{i}=1-p_{t r}^{i}$, and the probability that a collision occurs is $p_{c}^{i}=p_{t r}^{i}\left(1-p_{s u c}^{i}\right)$. We can further derive $\bar{T}_{B}$ and $\bar{T}_{S}$ using $p_{s}^{i}, p_{i}^{i}$ and $p_{c}^{i}$.

\section{Modeling schedule-based MAC: NAMA}

We choose NAMA as an example of schedule-based MAC schemes, because it completely eliminates the communication overheads of building the dynamic channel access schedule, except for collecting two-hop neighbor information, which is minimal compared with the task of collecting complete network topology information. In NAMA, a hash function is implemented at each node. The hash function takes a distinctive string of a node as input, and derives a random priority for each neighbor within two hops. The distinctive input string is the concatenation of the corresponding node identifier (collected through periodical HELLO messages) and the current time slot number such that the priority changes in different time slot. The channel access eligibility of each node is then determined by the node comparing its own priority with those of its two-hop neighbors. If a node has the highest priority, the node can access the channel within the corresponding time slot, while its two-hop neighbors are forbidden from channel access because they have lower priorities than the node. In order to find the correlation between the steady-state MAC layer scheduling rate $\left(\tau_{i}\right)$ and the successful transmission probability $q_{i}$, we first define the probability that the transmission schedule for node $i$ is collision-free $\left(\phi_{i}\right)$ as follows:

$$
\phi_{i}=P_{\{\text {no_conflicts } \mid \text { successinfo }\}} P_{\text {success info }}
$$

where $P_{\text {successinfo }}$ is the probability that the topology information exchange is successful in $i$ 's two-hop range. $P_{\{\text {no_conflicts } \mid \text { successinfo }\}}$ is the conditional probability of conflict-free scheduling given the correct neighbor information. For simplicity, We assume that the unsuccessful information exchange leads to transmission collisions. Then

$$
\tau_{i}=\phi_{i} q_{i}
$$

The time frame of NAMA can be further divided into a signal section and a data section. We denote the length of a time frame as

$$
T_{f}=N_{\text {signal }} t_{\text {signal }}+N_{\text {data }} t_{\text {data }}
$$

where $t_{\text {signal }}, t_{\text {data }}$ are the signal and data slot length; $N_{\text {signal }}, N_{\text {data }}$ are the number of signal and data slots, respectively.

Then according to Equation 6,

$$
P_{\text {success } \text { info }_{0}}=f\left(c_{i 0}^{r}\right) P\{\text { no neighbor transmits }\}
$$

In NAMA, each node randomly picks up a signal slot in the signal section to exchange topology information. 


$$
P\{\text { no neighbor transmits }\}=\left(1-\frac{1}{N_{\text {signal }}}\right)^{N_{2}^{i}-1}
$$

where $N_{2}^{i}$ is the number of neighbors within two hops of $i$. The conditional probability of node $i$ winning the node election given the correct topology information is:

$$
p_{s}^{i}=\frac{1}{N_{2}^{i}}
$$

Because NAMA uses the node identifier and the current time slot number as input to derive a random priority for every neighbor, which is unique within two hops, it eliminates the conflict scheduling given the correct topology information.

$$
\begin{gathered}
P_{\{\text {no_conflicts } \mid \text { successinfo }\}}=1 \\
\phi_{i}=p_{s}^{i} P_{\text {successinfo }}
\end{gathered}
$$

From Eq. (22) (24) (25) (28), we can obtain the correlation between $\tau_{i}$ and $q_{i}$. Given that the average number of times node $i$ could transmit successfully in one time frame is $\left\lceil\tau_{i} N_{\text {data }}\right\rceil$, the average service time is

$$
\bar{T}=\frac{T_{f}}{\left\lceil\tau_{i} N_{\text {data }}\right\rceil}
$$

\section{Model validation}

\begin{tabular}{|l|r|l|r|l|r|}
\hline \multicolumn{2}{|c|}{ 802.11 DCF MAC } & \multicolumn{2}{c|}{ NAMA MAC } & \multicolumn{2}{c|}{ PHY } \\
\hline$W_{\min }$ & 15 & $t_{\text {signal }}(\mu \mathrm{s})$ & 142 & Transmission rate $(\mathrm{Mbps})$ & 54 \\
$W_{\max }$ & 1023 & $N_{\text {signal }}$ & 500 & Transmission Power $(\mathrm{dBm})$ & 16 \\
RTS (bytes) & 30 & $t_{\text {data }}(\mu \mathrm{s})$ & 362.2 & Sensitivity of PHY $(\mathrm{dBm})$ & -69 \\
CTS (bytes) & 24 & $N_{\text {data }}$ & 1000 & Path loss factor $(\alpha)$ & 4 \\
ACK (bytes) & 24 & & & Transmission range $(\mathrm{m})$ & 79.58 \\
MAC Header (bytes) & 34 & & & Temperature (Kelvin) & 290 \\
Slot Time $(\mu \mathrm{sec})$ & 9 & & & Noise Factor & 10 \\
SIFS $(\mu \mathrm{sec})$ & 16 & & & & \\
\hline
\end{tabular}

Table 1. Simulation Parameters

\subsection{Simulation settings}

We compare the numerical results with the simulation results obtained from Qualnet (Qualnet Simulator, n.d.). The detailed simulation settings can be found in Table I. The packet length used is 1500 bytes. The duration of the simulation is 100 seconds. For the system throughput results, the simulations are repeated with ten different seeds to average the results for each scenario. We validate the numerical results against simulation experiments under two scenarios. The first scenario consists of 50 nodes distributed randomly across a $500 \times 500$ square meters area. The second scenario consists of 100 nodes distributed across a $800 \times 800$ square-meter area. The only constraint for the topology generation is that the network needs to be connected. For each topology, we set up multiple multi-hop CBR flows and vary the number of CBR flows to investigate the influence of packet forwarding methods. 


\subsection{Interaction between multipath routing and MAC}

We first examine the interaction of multipath routing formation and different MAC protocols.

\subsection{DCF}

\begin{tabular}{|l|l|l|l|l|}
\hline 50 nodes & $\begin{array}{l}\text { Node-disjoint } \\
\text { (analytical) } \\
(\mathrm{Mb} / \mathrm{s})\end{array}$ & $\begin{array}{l}\text { Node-disjoint } \\
\text { (simulation) } \\
(\mathrm{Mb} / \mathrm{s})\end{array}$ & $\begin{array}{l}\text { Link-disjoint } \\
\text { (analytical) } \\
(\mathrm{Mb} / \mathrm{s})\end{array}$ & $\begin{array}{l}\text { Link-disjoint } \\
\text { (simulation) } \\
(\mathrm{Mb} / \mathrm{s})\end{array}$ \\
\hline 10 flows & 32.12 & 28.24 & 32.55 & 33.17 \\
\hline 20 flows & 29.97 & 28.13 & 32.65 & 30.26 \\
\hline 30 flows & 25.19 & 23.37 & 29.99 & 27.45 \\
\hline 100 nodes & $\begin{array}{l}\text { Node-disjoint } \\
\text { (analytical) }\end{array}$ & $\begin{array}{l}\text { Node-disjoint } \\
\text { (simulation) }\end{array}$ & $\begin{array}{l}\text { Link-disjoint } \\
\text { (analytical) }\end{array}$ & $\begin{array}{l}\text { Link-disjoint } \\
\text { (simulation) }\end{array}$ \\
\hline 20 flows & 64.01 & 59.74 & 81.99 & 79.23 \\
\hline 30 flows & 65.21 & 61.21 & 77.04 & 81.49 \\
\hline 40 flows & 68.43 & 64.35 & 82.07 & 86.34 \\
\hline
\end{tabular}

Table 2. 802.11 DCF system throughput with different multipath packet forwarding

To demonstrate the model accuracy and provide some insights on system performance difference, we first examine the per-node throughput of 802.11 DCF, as Fig. 1 shows. Comparing Fig. 1(a) and Fig. 1(d), we observe that link-disjoint routing balances the traffic more evenly across different nodes. In other words, it is relatively easier to form congestion (bottlenecks) using node-disjoint routing. Because link-disjoint routing has a better spatial reuse throughout the network, it helps to form a better transmission scheduling at the MAC layer. This effect is amplified by a contention-based MAC. When we revisit the analytical model procedure shown in Eq. (1)-(21), the larger the contention neighbor set $V_{r}^{\prime}, C_{i}^{r}$, the lower the probability that a frame the transmission is successful, the lower the probability that a transmission schedule is collision free. The network-level congestions introduced by the routing protocols will introduce more contentions at the MAC layer, and the contention overheads around the bottlenecks will degrade the system performance significantly. For the above reasons, link-disjoint routing always outperforms node-disjoint routing when interacting with contention-based MACs, as Table 2 shows.

\subsubsection{NAMA}

\begin{tabular}{|l|l|l|l|l|}
\hline 50 nodes & $\begin{array}{l}\text { Node-disjoint } \\
\text { (analytical) } \\
(\mathrm{Mb} / \mathrm{s})\end{array}$ & $\begin{array}{l}\text { Node-disjoint } \\
\text { (simulation) } \\
(\mathrm{Mb} / \mathrm{s})\end{array}$ & $\begin{array}{l}\text { Link-disjoint } \\
\text { (analytical) } \\
(\mathrm{Mb} / \mathrm{s})\end{array}$ & $\begin{array}{l}\text { Link-disjoint } \\
\text { (simulation) } \\
(\mathrm{Mb} / \mathrm{s})\end{array}$ \\
\hline 10 flows & 125.54 & 117.29 & 123.27 & 121.03 \\
\hline 20 flows & 118.81 & 114.42 & 118.81 & 118.98 \\
\hline 30 flows & 116.02 & 112.13 & 115.78 & 116.37 \\
\hline 100 nodes & $\begin{array}{l}\text { Node-disjoint } \\
\text { (analytical) }\end{array}$ & $\begin{array}{l}\text { Node-disjoint } \\
\text { (simulation) }\end{array}$ & $\begin{array}{l}\text { Link-disjoint } \\
\text { (analytical) }\end{array}$ & $\begin{array}{l}\text { Link-disjoint } \\
\text { (simulation) }\end{array}$ \\
\hline 20 flows & 351.80 & 341.23 & 323.07 & 337.15 \\
\hline 30 flows & 320.94 & 313.42 & 314.85 & 316.38 \\
\hline 40 flows & 307.59 & 309.78 & 301.97 & 306.42 \\
\hline
\end{tabular}

Table 3. NAMA system throughput with different multipath packet forwarding

In contrast to contention-based MAC protocols, when a schedule-based MAC interacts with different multi-path packet forwarding disciplines, there is no significant difference between node-disjoint routing and link-disjoint routing. This is shown in Fig. 2 and Table 3. Revisiting the modeling process of the schedule-based MAC (Eq. (21)), its performance is mainly 


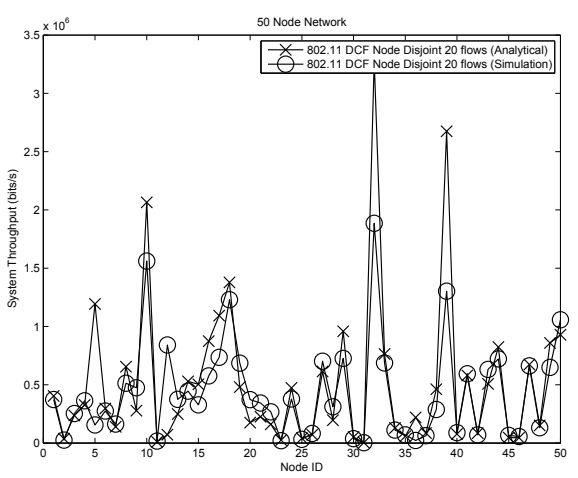

(a) 802.11 DCF with Node-Disjoint Routing Per-node Throughput (50 Nodes Network)

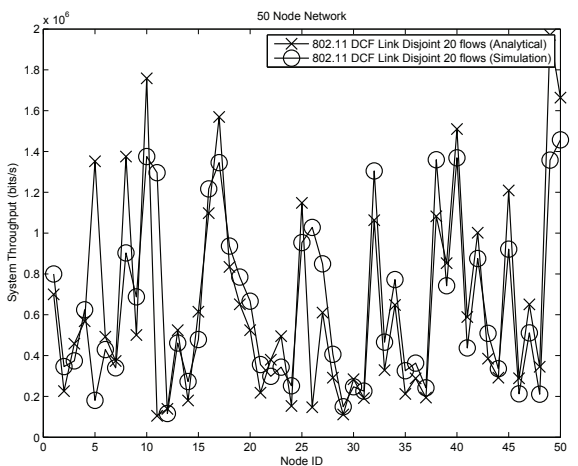

(b) 802.11 DCF with Link-Disjoint Routing Per-node Throughput (50 Nodes Network)
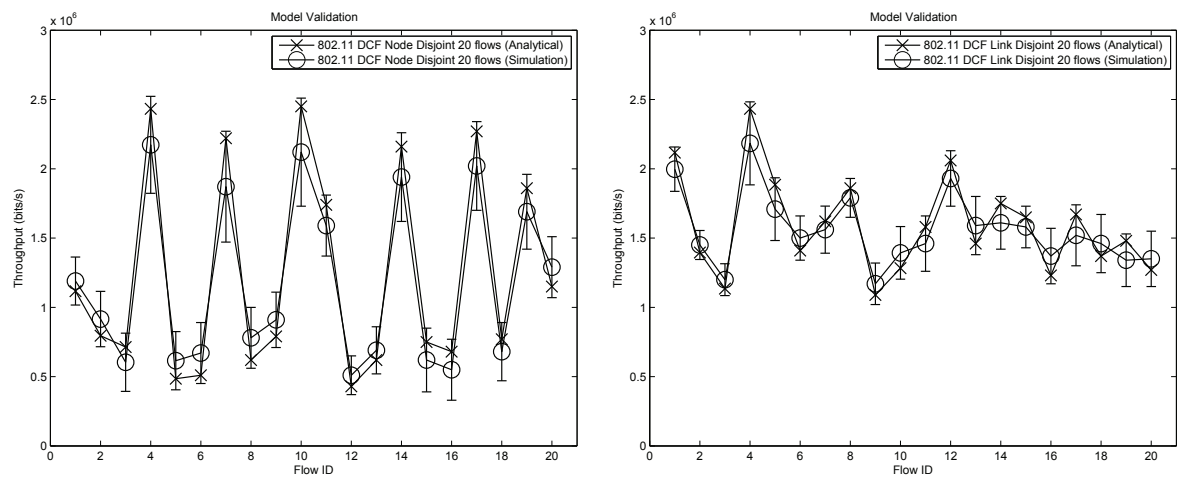

(c) 802.11 DCF with Node-Disjoint Routing (d) 802.11 DCF with Link-Disjoint Routing Per-flow Throughput (50 Nodes Network, 20 Per-flow Throughput (50 Nodes Network, 20 Flows) Flows)

Fig. 1. Model Validation: 802.11 DCF 


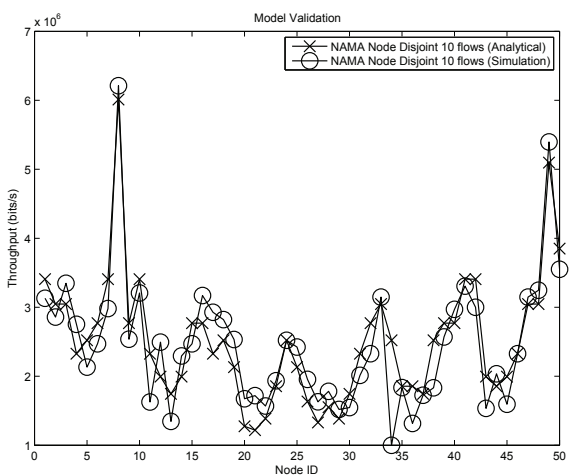

(a) NAMA with Node-Disjoint Routing Per-Node Throughput(50 Nodes Network, 10 flows)

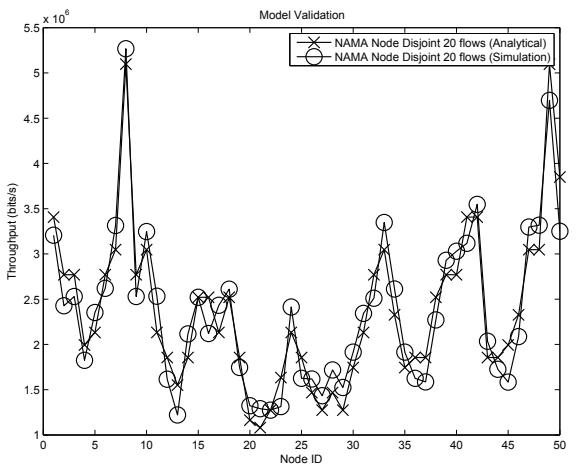

(b) NAMA with Node-Disjoint Routing Per-Node Throughput (50 Nodes Network, 20 flows)

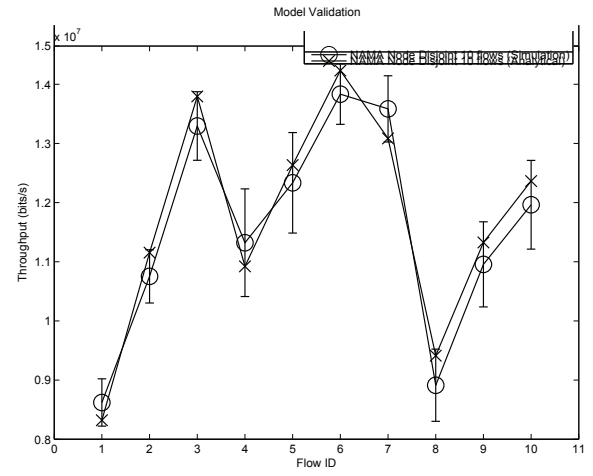

(c) NAMA with Node-Disjoint Routing Per-flow (d) Throughput(50 Nodes Network, 10 flows)

Fig. 2. Model Validation: NAMA

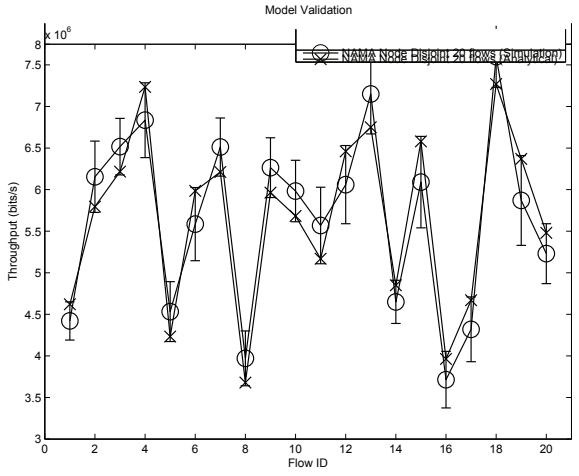

(d) NAMA with Node-Disjoint Routing Per-flow Throughput (50 Nodes Network, 20 flows) 
dependent on two factors: (a) The probability that the topology information exchange is successful; and (b) the conditional probability that a transmission schedule is collision-free given the correct topology information. Although the first factor is partially decided by the the number of contending nodes, the contention overheads will not increase linearly with the intensity of contentions, as contention-based MACs do. In other words, channel access contention may influence how quickly the collision-free transmission schedule is formed, while it does not influence the system throughput over the long-time run if the schedule mechanism works correctly. Another reason why schedule-based MACs are insensitive to the behavior of the routing protocol in our model is that the schedule rule is to increase the spatial/time reuse in the two-hop range to the largest extent, which alleviates the congestion introduced by routing protocols, if there are any.

\subsection{Interaction between opportunistic forwarding and MAC}

We now examine the impact of packet forwarding rules on different MAC protocols. For opportunistic forwarding, we vary different $p_{f}$ values. As Table 4 -Table 7 show, multiple-copy forwarding degrades system throughput while opportunistic forwarding could improve system throughput to some extent.

\subsection{DCF}

The system throughput comparisons of 802.11 DCF under different packet forwarding rules are shown in Table 4 and Table 5. We observe that, when combined with 802.11 DCF, opportunistic forwarding could enhance the system throughput for some $p_{f}$.

\begin{tabular}{|l|l|l|l|l|}
\hline 50 nodes & $\begin{array}{l}\text { Single-copy } \\
\text { forwarding } \\
\text { (analytical) } \\
(\mathrm{Mb} / \mathrm{s})\end{array}$ & $\begin{array}{l}\text { Single-copy } \\
\text { forwarding } \\
\text { (simulation) } \\
(\mathrm{Mb} / \mathrm{s})\end{array}$ & $\begin{array}{l}\text { Multiple-copy } \\
\text { forwarding } \\
\text { (analytical) } \\
(\mathrm{Mb} / \mathrm{s})\end{array}$ & $\begin{array}{l}\text { Multiple-copy } \\
\text { forwarding } \\
\text { (simulation) } \\
(\mathrm{Mb} / \mathrm{s})\end{array}$ \\
\hline 10 flows & 22.38 & 21.75 & 16.28 & 16.59 \\
\hline 20 flows & 20.09 & 19.26 & 16.33 & 15.14 \\
\hline 30 flows & 18.41 & 18.78 & 14.99 & 13.73 \\
\hline 100 nodes & $\begin{array}{l}\text { Single-copy } \\
\text { forwarding } \\
\text { (analytical) } \\
\text { (Mb/s) }\end{array}$ & $\begin{array}{l}\text { Single-copy } \\
\text { forwarding } \\
\text { (simulation) } \\
(\mathrm{Mb} / \mathrm{s})\end{array}$ & $\begin{array}{l}\text { Multiple-copy } \\
\text { forwarding } \\
\text { (analytical) } \\
(\mathrm{Mb} / \mathrm{s})\end{array}$ & $\begin{array}{l}\text { Multiple-copy } \\
\text { forwarding } \\
\text { (simulation) } \\
\text { (Mb/s) }\end{array}$ \\
\hline 20 flows & 64.01 & 59.74 & 41.99 & 36.62 \\
\hline 30 flows & 65.20 & 61.26 & 38.52 & 41.75 \\
\hline 40 flows & 68.43 & 64.35 & 41.04 & 43.17 \\
\hline
\end{tabular}

Table 4. 802.11 DCF system throughput with different routing forwarding rules

\subsubsection{NAMA}

The system throughput results for NAMA using different packet forwarding rules are shown in Table 6 and Table 7. We observe that, in contrast to the results shown in Table 4, when combining NAMA with opportunistic forwarding, the improvement of system throughput is quite minor. To understand the reason for the differences in the results obtained with 802.11 DCF and NAMA, we need to revisit how opportunistic forwarding impacts the system performance. First, opportunistic forwarding increases the system reliability by using multiple successors to forward duplicate packets. This is at the cost of consuming more system resources, which is the major reason that single-copy forwarding always outperforms multi-copy forwarding in terms of throughput. Second, one key aspect of opportunistic forwarding is that the node that forwards a packet is determined on-the-fly, which means 
that the contention neighbor sets $V_{r}^{\prime}$ and $C_{i}^{r}$ change over time. This is desirable when a contention-based MAC is used, because it increases the robustness of the end-to-end transmissions and could accommodate channel fluctuations. However, it is more difficult for a schedule-based MAC to build a collision-free transmission schedule. What is more, the schedule-based MAC also alleviates the collisions of transmissions and physical-layer interference to some extent. As a result, the gain of the opportunistic forwarding is reduced when combined with a schedule-based MAC, as Table 6 shows. Given that most opportunistic routing schemes have been evaluated over contention-based MAC (802.11 DCF or its extensions) (Biswas \& Morris, 2005) (Chachulski et al., 2007), the results obtained in this paper motivate us to rethink how to leverage opportunistic forwarding using generic MAC protocols. From Table 5 and Table 7, we can also find the system throughput does not increase linearly with $p_{f}$. This is because a larger $p_{f}$ not only increases the reliability of end-to-end delivery, but also the contentions within the two-hop range. For each simulation experiment, there is an optimal $p_{f}$, which is dependent on the topology and the traffic pattern.

\section{Conclusion}

We introduced a novel analytical model to study the interactions of MAC and packet forwarding schemes in multi-hop wireless networks. Our model captures different aspects of the protocol interaction procedure and different information feedback across layers, and permits us to study how the use of multiple paths and packet forwarding rules influence the performance of different MAC protocols. We validated our analytical model by comparing its results against simulation experiments. Given the good match between analytical and simulation results, it follows that the results obtained from the analytical model can provide valuable insights on the interaction between MAC and routing protocol and how protocol stacks could be optimized.

\begin{tabular}{|c|c|c|c|c|}
\hline 50 nodes & $\begin{array}{l}p_{f}=0.2 \\
\text { (analytical) } \\
(\mathrm{Mb} / \mathrm{s})\end{array}$ & $\begin{array}{l}p_{f}=0.2 \\
(\text { simulation }) \\
(\mathrm{Mb} / \mathrm{s})\end{array}$ & $\begin{array}{l}p_{f}=0.4 \\
\text { (analytical)(Mb }\end{array}$ & $\begin{array}{l}p_{f}=0.4 \\
\text { /\$simulation) } \\
(\mathrm{Mb} / \mathrm{s})\end{array}$ \\
\hline 10 flows & 26.76 & 28.09 & 24.25 & 22.62 \\
\hline 20 flows & 25.15 & 26.17 & 22.78 & 24.47 \\
\hline 30 flows & 25.03 & 24.72 & 21.96 & 24.08 \\
\hline 50 nodes & $\begin{array}{l}p_{f}=0.6 \\
\text { (analytical) } \\
(\mathrm{Mb} / \mathrm{s})\end{array}$ & $\begin{array}{l}p_{f}=0.6 \\
(\text { simulation) } \\
(\mathrm{Mb} / \mathrm{s})\end{array}$ & $\begin{array}{l}p_{f}=0.8 \\
\text { (analytical) } \\
(\mathrm{Mb} / \mathrm{s})\end{array}$ & $\begin{array}{l}p_{f}=0.8 \\
\text { (simulation) } \\
(\mathrm{Mb} / \mathrm{s})\end{array}$ \\
\hline 10 flows & 21.09 & 22.55 & 18.43 & 19.13 \\
\hline 20 flows & 19.27 & 20.76 & 17.06 & 17.88 \\
\hline 30 flows & 18.45 & 19.87 & 15.11 & 16.52 \\
\hline 100 nodes & $\begin{array}{l}p_{f}=0.2 \\
(\text { analytical) } \\
(\mathrm{Mb} / \mathrm{s})\end{array}$ & $\begin{array}{l}p_{f}=0.2 \\
(\text { simulation) } \\
(\mathrm{Mb} / \mathrm{s})\end{array}$ & $\begin{array}{l}p_{f}=0.4 \\
(\text { analytical })(\mathrm{Mb}\end{array}$ & $\begin{array}{l}p_{f}=0.4 \\
\text { /\$simulation) } \\
(\mathrm{Mb} / \mathrm{s})\end{array}$ \\
\hline 20 flows & 76.18 & 79.69 & 67.26 & 71.25 \\
\hline 30 flows & 75.27 & 78.85 & 65.13 & 69.23 \\
\hline 40 flows & 78.31 & 78.26 & 66.89 & 69.28 \\
\hline 100 nodes & $\begin{array}{l}p_{f}=0.6 \\
\text { (analytical) } \\
(\mathrm{Mb} / \mathrm{s})\end{array}$ & $\begin{array}{l}p_{f}=0.6 \\
\text { (simulation) } \\
(\mathrm{Mb} / \mathrm{s})\end{array}$ & $\begin{array}{l}p_{f}=0.8 \\
\text { (analytical) } \\
(\mathrm{Mb} / \mathrm{s})\end{array}$ & $\begin{array}{l}p_{f}=0.8 \\
\text { (simulation) } \\
(\mathrm{Mb} / \mathrm{s})\end{array}$ \\
\hline 20 flows & 59.22 & 63.54 & 49.04 & 48.15 \\
\hline 30 flows & 60.91 & 62.08 & 45.16 & 41.21 \\
\hline 40 flows & 58.34 & 62.99 & 46.60 & 43.12 \\
\hline
\end{tabular}

Table 5. 802.11 DCF system throughput with different opportunistic forwarding $\left(p_{f}\right)$ 


\begin{tabular}{|l|l|l|l|l|}
\hline 50 nodes & $\begin{array}{l}\text { Single-copy } \\
\text { forwarding } \\
\text { (analytical) } \\
(\mathrm{Mb} / \mathrm{s})\end{array}$ & $\begin{array}{l}\text { Single-copy } \\
\text { forwarding } \\
\text { (simulation) } \\
(\mathrm{Mb} / \mathrm{s})\end{array}$ & $\begin{array}{l}\text { Multiple-copy } \\
\text { forwarding } \\
\text { (analytical) } \\
(\mathrm{Mb} / \mathrm{s})\end{array}$ & $\begin{array}{l}\text { Multiple-copy } \\
\text { forwarding } \\
\text { (simulation) } \\
(\mathrm{Mb} / \mathrm{s})\end{array}$ \\
\hline 10 flows & 96.02 & 91.08 & 61.64 & 66.53 \\
\hline 20 flows & 92.11 & 86.39 & 59.40 & 55.49 \\
\hline 30 flows & 86.25 & 82.01 & 57.89 & 53.26 \\
\hline 100 nodes & $\begin{array}{l}\text { Single-copy } \\
\text { forwarding } \\
\text { (analytical) } \\
(\mathrm{Mb} / \mathrm{s})\end{array}$ & $\begin{array}{l}\text { Single-copy } \\
\text { forwarding } \\
\text { (simulation) } \\
(\mathrm{Mb} / \mathrm{s})\end{array}$ & $\begin{array}{l}\text { Multiple-copy } \\
\text { forwarding } \\
\text { (analytical) } \\
(\mathrm{Mb} / \mathrm{s})\end{array}$ & $\begin{array}{l}\text { Multiple-copy } \\
\text { forwarding } \\
\text { (simulation) } \\
\text { (Mb/s) }\end{array}$ \\
\hline 20 flows & 265.14 & 254.39 & 161.54 & 168.58 \\
\hline 30 flows & 243.28 & 231.76 & 157.43 & 149.19 \\
\hline 40 flows & 214.87 & 203.91 & 150.99 & 143.21 \\
\hline
\end{tabular}

Table 6. NAMA system throughput with different routing forwarding rules

\begin{tabular}{|c|c|c|c|c|}
\hline 50 nodes & $\begin{array}{l}p_{f}=0.2 \\
\text { (analytical) } \\
(\mathrm{Mb} / \mathrm{s})\end{array}$ & $\begin{array}{l}p_{f}=0.2 \\
(\text { simulation) } \\
(\mathrm{Mb} / \mathrm{s})\end{array}$ & $\begin{array}{l}p_{f}=0.4 \\
\text { (analytical) } \\
(\mathrm{Mb} / \mathrm{s})\end{array}$ & $\begin{array}{l}p_{f}=0.4 \\
\text { (simulation) } \\
(\mathrm{Mb} / \mathrm{s})\end{array}$ \\
\hline 10 flows & 98.10 & 104.28 & 83.37 & 80.19 \\
\hline 20 flows & 96.35 & 100.02 & 80.29 & 84.45 \\
\hline 30 flows & 88.24 & 96.23 & 78.06 & 81.27 \\
\hline 50 nodes & $\begin{array}{l}p_{f}=0.6 \\
\text { (analytical) } \\
(\mathrm{Mb} / \mathrm{s})\end{array}$ & $\begin{array}{l}p_{f}=0.6 \\
(\text { simulation) } \\
(\mathrm{Mb} / \mathrm{s})\end{array}$ & $\begin{array}{l}p_{f}=0.8 \\
(\text { analytical) } \\
(\mathrm{Mb} / \mathrm{s})\end{array}$ & $\begin{array}{l}p_{f}=0.8 \\
(\text { simulation) } \\
(\mathrm{Mb} / \mathrm{s})\end{array}$ \\
\hline 10 flows & 75.16 & 79.85 & 66.26 & 70.24 \\
\hline 20 flows & 72.32 & 71.58 & 68.84 & 66.59 \\
\hline 30 flows & 70.35 & 68.73 & 64.56 & 68.16 \\
\hline 100 nodes & $\begin{array}{l}p_{f}=0.2 \\
\text { (analytical) } \\
(\mathrm{Mb} / \mathrm{s})\end{array}$ & $\begin{array}{l}p_{f}=0.2 \\
(\text { simulation) } \\
(\mathrm{Mb} / \mathrm{s})\end{array}$ & $\begin{array}{l}p_{f}=0.4 \\
(\text { analytical })(\mathrm{Mb}\end{array}$ & $\begin{array}{l}p_{f}=0.4 \\
\text { (s)imulation) } \\
(\mathrm{Mb} / \mathrm{s})\end{array}$ \\
\hline 20 flows & 270.18 & 262.39 & 231.04 & 225.01 \\
\hline 30 flows & 246.23 & 234.85 & 217.50 & 219.74 \\
\hline 40 flows & 219.72 & 231.80 & 202.59 & 210.88 \\
\hline 100 nodes & $\begin{array}{l}p_{f}=0.6 \\
\text { (analytical) } \\
(\mathrm{Mb} / \mathrm{s})\end{array}$ & $\begin{array}{l}p_{f}=0.6 \\
(\text { simulation) } \\
(\mathrm{Mb} / \mathrm{s})\end{array}$ & $\begin{array}{l}p_{f}=0.8 \\
\text { (analytical) } \\
(\mathrm{Mb} / \mathrm{s})\end{array}$ & $\begin{array}{l}p_{f}=0.8 \\
\text { (simulation) } \\
(\mathrm{Mb} / \mathrm{s})\end{array}$ \\
\hline 20 flows & 196.16 & 182.40 & 182.55 & 178.14 \\
\hline 30 flows & 185.24 & 170.16 & 180.61 & 172.06 \\
\hline 40 flows & 183.44 & 174.33 & 176.18 & 169.58 \\
\hline
\end{tabular}

Table 7. NAMA system throughput with different opportunistic forwarding $\left(p_{f}\right)$

\section{References}

Abramson, N. (1970). The ALOHA system-another alternative for computer communications, AFIPS Conf. Proc., Vol. 37, FJCC, pp. 281-285.

Abramson, N. (1977). The throughput of packet broadcast channels, IEEE Trans. on Communications COM-25(1): 117-128.

Arnbak, J. C. \& Blitterswijk, W. V. (1987). Capacity of slotted aloha in rayleigh-fading channels, IEEE Journal on Selected Areas in Communications SAC-5(2): 261-269.

Bai, F., Sadagopan, N. \& Helmy, A. (2003). IMPORTANT: A framework to systematically analyze the Impact of Mobility on Performance of RouTing protocols for Ad Hoc Networks, Proc. IEEE INFOCOM, San Francisco, CA, USA, pp. 825-835. 
Barghavan, V., Demers, A., Shenker, S. \& Zhang, L. (1994). MACAW: A media access protocol for wireless LAN's, Proc. of ACM SIGCOMM '94, pp. 212-225.

Barrett, C., Drozda, M., Marathe, A. \& Marathe, M. (2003). Characterizing the Interaction between Routing and MAC Protocols in Ad-Hoc Networks, Proceedings of the ACM International Symposium on Mobile Ad Hoc Networking and Computing (Mobihoc), Lausanne, Switzerland, pp. 92-103.

Bianchi, G. (2000). Performance analysis of the IEEE 802.11 distributed coordination function, IEEE Journal on Selected Areas in Communications 18(3): 535-547.

Biswas, S. \& Morris, R. (2005). ExOR: Opportunistic Multi-hop Routing for Wireless Networks, Proc. ACM SIGCOMM.

Boorstyn, R. R., Kershenbaum, A., Maglaris, B. \& Sahin, V. (1987). Throughput analysis in multihop CSMA packet radio networks, IEEE Trans. on Communications COM-35(3): 267-274.

Cali, F., Conti, M. \& Gregori, E. (2000). Dynamic tuning of the IEEE 802.11 protocol to achieve a theoretical throughput limit, IEEE/ACM Tran. on Networking 8(6): 785-799.

Carvalho, M. M. \& Garcia-Luna-Aceves, J. J. (2003). Delay analysis of IEEE 802.11 in single-hop networks, Proc. 11th IEEE International Conference on Network Protocols (ICNP), Atlanta, USA, pp. 146-155.

Carvalho, M. M. \& Garcia-Luna-Aceves, J. J. (2004). A Scalable Model for Channel Access Protocols in Multihop Ad Hoc Networks, Proc. ACM Mobicom, Philadelphia, USA.

Chachulski, S., Jennings, M., Katti, S. \& Katabi, D. (2007). Trading structure for randomness in wireless opportunistic routing, Proc. ACM SIGCOMM.

Chhaya, H. \& Gupta, S. (1997). Performance modeling of asynchronous data transfer methods of IEEE 802.11 MAC protocol, Wireless Networks 3: 217-234.

Colvin, A. (1983). CSMA with collision avoidance, Computer Commun. 6(5): 227-235.

Das, S., Perkins, C. \& Royer, E. (2000). Performance Comparison of Two On-demand Routing Protocols for Ad Hoc Networks, Proc. IEEE Conference on Computer Communications (INFOCOM), Tel Aviv, Israel, pp. 3-12.

Das, S. R., Perkins, C. E., Royer, E. M. \& Marina, M. K. (2001). Performance comparison of two on-demand routing protocols for ad hoc networks, IEEE Personal Communications Magazine, special issue on Mobile Ad Hoc Networks.

Davis, D. H. \& Gronemeyer, S. A. (1980). Performance of slotted ALOHA random access with delay capture and randomized time of arrival, IEEE Trans. Commun. COM-28(5): 703-710.

Foh, C. \& Zukerman, M. (2002). Performance analysis of the IEEE 802.11 MAC protocol, Proc. of the European Wireless 2002 Conference, Florence, Italy, pp. 184-190.

Fullmer, C. L. \& Garcia-Luna-Aceves, J. J. (1995). Floor acquisition multiple access (FAMA) for packet-radio networks, SIGCOMM '95, Cambridge, MA (USA), pp. 262-273.

Fullmer, C. L. \& Garcia-Luna-Aceves, J. J. (1997). Solutions to hidden terminal problems in wireless networks, Proc. ACM SIGCOMM 97, Cannes, France.

Gitman, I. (1975). On the capacity of slotted ALOHA networks and some desigh problems, IEEE Trans. on Communications COM-23(3): 305-317.

Karn, P. (1990). MACA - a new channel access method for packet radio, ARRL/CRRL Amateur Radio 9th Computer Networking Conference, pp. 134-140.

Kim, H. \& Hou, J. C. (2003). Improving protocol capacity with model-based frame scheduling in IEEE 802.11-operated WLANs, Proc. of the 9th ACM International Conference on Mobile Computing and Networking (MOBICOM), San Diego, CA, USA, pp. 190-204. 
Kleinrock, L. \& Lam, S. S. (1975). Packet switching in a multiaccess broadcast channel: Performance evaluation, IEEE Trans. on Communications COM-23(4): 410-423.

Kleinrock, L. \& Tobagi, F. A. (1975). Packet switching in radio channels: Part I - carrier sense multiple-access modes and their throughput-delay characteristics, IEEE Trans. on Communications COM-23(12): 1400-1416.

Lee, S. \& Gerla, M. (2001). Split Multipath Routing with Maximally Disjoint Paths in Ad Hoc Networks, Proceedings of the IEEE ICC, pp. 3201-3205.

Lo, W. F. \& Mouftah, H. T. (1984). Carrier sense multiple access with collision detection for radio channels, IEEE 13th Int'l Commun. and Energy Conf., pp. 244-247.

Marina, M. \& Das, S. (2001). On-demand Multipath Distance Vector Routing in Ad Hoc Networks, Proceedings of IEEE International Conference on Network Protocols (ICNP), pp. 14-23.

Musser, M. \& Daigle, J. (1982). Throughput analysis of an asynchronous code division multiple access (CDMA) system, Proc. ICC'82, Philadelphia, PA.

Nasipuri, A., Castaeda, R. \& Das, S. R. (2001). Performance of Multipath Routing for On-demand Protocols in Mobile Ad Hoc Networks, Mob. Netw. Appl. 6(4): 339-349.

Pursley, M. (1983). Throughput of frequency-hopped spread spectrum communications for packet radio networks, Proc. 1983 CISS, John Hopkins Univ., Baltimore, MD, USA.

Qualnet Simulator (n.d.). Scalable Network Technologies, http:/ / www.scalable-networks.com/.

Raychauduri, D. (1981). Performance analysis of random access packet-switched code division multiple access systems, IEEE Trans. Commun. COM-29(6): 895-901.

Roberts, L. G. (1975). ALOHA packet system with and without slots and capture, Comput. Commun. Rev. 5: 28-42.

Royer, E., Lee, S. \& Perkins, C. (2000). The Effects of MAC Protocols on Ad hoc Network Communications, Proc. IEEE Wireless Communications and Networking Conference(WCNC), Chicago, IL.

Shepard, T. J. (1996). A channel access scheme for large dense packet radio networks, Proc. of ACM SIGCOMM, ACM Press, pp. 219-230.

Tobagi, F. A. (1980a). Analysis of a two-hop centralized packet radio network-part I: Slotted ALOHA, IEEE Trans. Commun. COM-28(2): 196-207.

Tobagi, F. A. (1980b). Analysis of a two-hop centralized packet radio network-part II: Carrier sense multiple access, IEEE Trans. Commun. COM-28(2): 208-216.

Tobagi, F. A. \& Brazio, J. M. (1983). Throughput analysis of multihop packet radio network under various channel access schemes, Proc. INFOCOM'83, San Diego, CA.

Tobagi, F. A. \& Kleinrock, L. (1975). Packet switching in radio channels: Part II - the hidden terminal problem in carrier sense multiple-access modes and the busy-tone solution, IEEE Trans. on Communications COM-23(12): 1417-1433.

Tse, D. \& Hanly, S. (1999). Linear multiuser receivers: Effective interference, effective bandwidth and user capacity, IEEE Trans. Information Theory 45(2): 641-657.

Vadde, K. K. \& Syrotiuk, V. R. (2004). Factor Interaction on Service Delivery in Mobile Ad Hoc Networks, IEEE Journal on Selected Areas in Communications pp. 1335-1346.

Vadde, K. K., Syrotiuk, V. R. \& Montgomery, D. C. (2006). Optimizing Protocol Interaction using Response Surface Methodology, IEEE Transactions on Mobile Computing 5: 627-639.

Wang, Y. \& Garcia-Luna-Aceves, J. J. (2002). Performance of collision avoidance protocols in single-channel ad hoc networks, Proc. of 10th IEEE International Conference on Network 
Protocols (ICNP), Paris, France.

Wu, L. \& Varshney, P. (1999). Performance analysis of CSMA and BTMA protocols in multihop networks (I). single channel case, Information Sciences, Elsevier Sciences Inc. 120: 159-177.

Ye, Z., Krishnamurthy, S. V. \& Tripathi, S. K. (2003). A Framework for Reliable Routing in Mobile Ad Hoc Networks, Proceedings of the IEEE INFOCOM, pp. 270-280. 


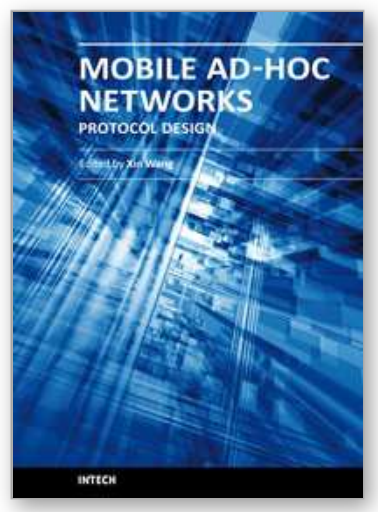

\author{
Mobile Ad-Hoc Networks: Protocol Design \\ Edited by Prof. Xin Wang
}

ISBN 978-953-307-402-3

Hard cover, 656 pages

Publisher InTech

Published online 30, January, 2011

Published in print edition January, 2011

Being infrastructure-less and without central administration control, wireless ad-hoc networking is playing a more and more important role in extending the coverage of traditional wireless infrastructure (cellular networks, wireless LAN, etc). This book includes state-of-the-art techniques and solutions for wireless ad-hoc networks. It focuses on the following topics in ad-hoc networks: quality-of-service and video communication, routing protocol and cross-layer design. A few interesting problems about security and delay-tolerant networks are also discussed. This book is targeted to provide network engineers and researchers with design guidelines for large scale wireless ad hoc networks.

\title{
How to reference
}

In order to correctly reference this scholarly work, feel free to copy and paste the following:

Xin Wang, J.J. Garcia-Luna-Aceves, Hamid R. Sadjadpour (2011). Performance Modeling of MAC and Multipath Routing Interactions in Multi-hop Wireless Networks, Mobile Ad-Hoc Networks: Protocol Design, Prof. Xin Wang (Ed.), ISBN: 978-953-307-402-3, InTech, Available from: http://www.intechopen.com/books/mobilead-hoc-networks-protocol-design/performance-modeling-of-mac-and-multipath-routing-interactions-in-multihop-wireless-networks

\section{INTECH}

open science | open minds

\section{InTech Europe}

University Campus STeP Ri

Slavka Krautzeka 83/A

51000 Rijeka, Croatia

Phone: +385 (51) 770447

Fax: +385 (51) 686166

www.intechopen.com

\section{InTech China}

Unit 405, Office Block, Hotel Equatorial Shanghai

No.65, Yan An Road (West), Shanghai, 200040, China

中国上海市延安西路65号上海国际贵都大饭店办公楼405单元

Phone: +86-21-62489820

Fax: +86-21-62489821 
(C) 2011 The Author(s). Licensee IntechOpen. This chapter is distributed under the terms of the Creative Commons Attribution-NonCommercialShareAlike-3.0 License, which permits use, distribution and reproduction for non-commercial purposes, provided the original is properly cited and derivative works building on this content are distributed under the same license. 